\title{
Activity and Habitat Use of Chimpanzees (Pan troglodytes verus) in the Anthropogenic Landscape of Bossou, Guinea, West Africa
}

\author{
Nicola Bryson-Morrison ${ }^{1}$ (D) \\ Joseph Tzanopoulos ${ }^{2,3}$. Tetsuro Matsuzawa ${ }^{4}$. \\ Tatyana Humle ${ }^{2}$
}

Received: 12 May 2016 / Accepted: 6 December 2016 / Published online: 30 January 2017

(C) The Author(s) 2017. This article is published with open access at Springerlink.com

\begin{abstract}
Many primate populations inhabit anthropogenic landscapes. Understanding their long-term ability to persist in such environments and associated real and perceived risks for both primates and people is essential for effective conservation planning. Primates in forest-agricultural mosaics often consume cultivars to supplement their diet, leading to potentially negative encounters with farmers. When crossing roads, primates also face the risk of encounters with people and collision with vehicles. Chimpanzees (Pan troglodytes verus) in Bossou, Guinea, West Africa, face such risks regularly. In this study, we aimed to examine their activity budget across habitat types and the influence of anthropogenic risks associated with cultivated fields, roads, and paths on their foraging behavior in noncultivated habitat. We conducted 6-h morning or afternoon follows daily from April 2012 to March 2013. Chimpanzees preferentially used forest habitat types for traveling and resting and highly disturbed habitat types for socializing. Wild fruit and crop availability influenced seasonal habitat use for foraging. Overall, chimpanzees preferred mature forest for all activities. They showed a
\end{abstract}

Handling Editor: Kimberley Hockings

Electronic supplementary material The online version of this article (doi:10.1007/s10764-016-9947-4) contains supplementary material, which is available to authorized users.

Nicola Bryson-Morrison nb258@kent.ac.uk

1 School of Anthropology and Conservation, University of Kent, Canterbury, Kent CT2 7NR, UK

2 Durrell Institute of Conservation and Ecology, School of Anthropology and Conservation, University of Kent, Canterbury, Kent CT2 7NR, UK

3 Kent's Interdisciplinary Centre for Spatial Studies (KISS), University of Kent, Canterbury, Kent CT2 7NR, UK

4 Primate Research Institute, Kyoto University, Inuyama, Aichi 484-8506, Japan 
significant preference for foraging at $>200 \mathrm{~m}$ from cultivated fields compared to 0 $100 \mathrm{~m}$ and 101-200 m, with no effect of habitat type or season, suggesting an influence of associated risk. Nevertheless, the chimpanzees did not actively avoid foraging close to roads and paths. Our study reveals chimpanzee reliance on different habitat types and the influence of human-induced pressures on their activities. Such information is critical for the establishment of effective land use management strategies in anthropogenic landscapes.

Keywords Forest-agricultural mosaic $\cdot$ Habitat selection $\cdot$ Human-wildlife coexistence Risk perception

\section{Introduction}

Habitat loss due to deforestation and land conversion are major causes of the decline of nonhuman primate (hereafter primate) species (Chapman and Peres 2001; Estrada 2013). The continued degradation of forested areas, together with ongoing human population growth across most primate range countries, means that many primate populations now occur in forest-agricultural mosaics (Estrada 2013). Primates inhabiting these landscapes face multiple challenges including habitat degradation and fragmentation, human infrastructures such as roads or settlements, and increased encounters with people (Hockings et al. 2015). Their long-term survival critically depends on their ability to adapt to these human-dominated environments (IsabiryeBasuta and Lwanga 2008), as well as people's tolerance of and behavior toward primates within these landscapes (Hill and Webber 2010).

Recent studies have revealed that many primates prefer areas with lower disturbance levels [chimpanzees (Pan troglodytes) and sooty mangabeys (Cercocebus atys): Brncic et al. 2015; bonobos (Pan paniscus): Hickey et al. 2013; chimpanzees, bonobos, and gorillas (Gorilla spp.): Junker et al. 2012; chimpanzees: Plumptre et al. 2010; mountain gorillas (G. beringei beringei): van Gils and Kayijamahe 2010; orangutans (Pongo pygmaeus): Wich et al. 2012]. These broad-scale studies have yielded important insights into the factors that influence the spatial distribution of a species on a national or regional scale. However, species persistence across landscapes can be scale dependent (Sawyer and Brashares 2013), and a finer-scale approach is required for understanding the effects of anthropogenic influences and disturbances on primate habitat use and behavioral flexibility (Bortolamiol et al. 2016). Such studies can help to inform land use planning aimed at balancing species conservation and development at a local scale in human-dominated environments.

Primate species show variable and multiple responses to environmental disturbances. Human-induced modifications in habitat quality can cause changes in primate feeding behavior, dietary diversity and resource use (Campbell-Smith et al. 2011; Guzmán et al. 2016; Lee 1997; Ménard et al. 2014; Pozo-Montuy et al. 2013; Riley 2007; Singh et al. 2001; Tutin 1999; Wong et al. 2006). Primate responses to the availability of wild and anthropogenic food sources are often species and/or context specific (McLennan and Hockings 2014). Some primates predominantly use areas of their home range in locations where important wild resources still remain (Heiduck 2002; Leighton 1993; Li 2004; O’Brien and Kinnaird 1997; Raboy and Dietz 2004; 
Riley 2008; Terada et al. 2015; Tweheyo et al. 2004). However, highly clumped and predictable food resources, such as exotic vegetation, cultivars, and human food waste, can also attract primates (Bortolamiol et al. 2016; Duvall 2008; Hill 2005; Hockings et al. 2009; Hoffman and O'Riain 2011; McKinney 2011).

Changes in primate habitat use, ranging, and activity budgets are often associated with anthropogenically disturbed environments. In locations where habitat quality and food resource availability are diminished, primates tend to exhibit larger home ranges and daily path lengths and spend more time traveling and less time resting and feeding, e.g., white-faced capuchins (Cebus capucinus: McKinney 2011) and long-tailed macaques (Macaca fascicularis: Sha and Hanya 2013). Conversely, primates that have access to, and use, spatially and temporally abundant human food sources tend to have smaller home ranges, spend less time traveling and foraging, and more time resting, e.g., yellow baboons (Papio cynocephalus: Altmann and Muruthi 1988), ringtailed lemurs (Lemur catta: Gabriel 2013), and vervets (Chlorocebus pygerythrus: Saj et al. 1999). Most studies to date have focused on how habitat quality affects general patterns of primate activity budget allocation (Gabriel 2013; Guzmán et al. 2016; McKinney 2011; Riley 2007, 2008), while only a few have examined nonforaging activities across available habitat types within a landscape and within a single group (Terada et al. 2015). The preferences primates show for allocating activities to different habitats can provide insights into the relative value of these habitats, as well as species' ability to adapt to habitat change (Palminteri and Peres 2012; Porter et al. 2007).

Risk and risk perception can also influence primate activity and range use. For example, predation risk influenced the use of different habitat types by chacma baboons (Papio ursinus) for resting and grooming (Cowlishaw 1997). Many primate species use their ranges strategically to offset the risk of predation with food acquisition (Hill 2016). Feeding is a risky behavior, and where individuals choose to feed can impact fitness and survival as much as what they choose to feed on (Lambert and Rothman 2015). It is likely that primates inhabiting anthropogenic landscapes aim to use habitats in such a way as to balance nutritional requirements with avoiding potential risks associated with human-induced pressures. Such risks can include negative interactions between farmers and primates due to cultivar foraging (Brncic et al. 2010; Hill 2000; Hockings et al. 2009; Hockings and Sousa 2013; McLennan 2013; Tweheyo et al. 2005), hunting pressure (Blake et al. 2007; Poulsen et al. 2009; Robinson et al. 1999), and risks from collisions with vehicles during road crossing (Cibot et al. 2015; McLennan and Asiimwe 2016). Chimpanzees, in particular, show a variety of adaptive behaviors in response to perceived risks associated with anthropogenic environments (Hockings et al. 2015), many of which have been likened to predator avoidance strategies (Hockings et al. 2006; Sakura 1994; Takemoto 2002). When foraging on cultivars, chimpanzees may increase group cohesiveness and vigilance behaviors (Hockings et al. 2007, 2012), vocalize less (Wilson et al. 2007), and forage at night to reduce the risk of detection by farmers (Krief et al. 2014). Chimpanzees also adapt their grouping patterns and behavior before and during road crossings (Cibot et al. 2015; Hockings 2011). 
Recent studies have demonstrated that primates display signs of anxiety and stress when faced with anthropogenic pressures (chimpanzees: Hicks et al. 2012; Hockings 2011; Hockings et al. 2006 and mountain gorillas: Muyambi 2005); some populations also show an increase in cortisol, a hormone that is released to buffer individuals in the short term from the effects of acute stress (Cyr and Romero 2008; Wingfield and Romero 2010), concentration levels [vervets: Fourie et al. 2015; spider monkeys (Ateles geoffroyi yucatanensis): Rangel-Negrín et al. 2009]. Prolonged exposure to increased levels of anxiety and stress has negative impacts on fitness (Sapolsky et al. 2000). However, besides cultivar foraging and road crossing, we have a limited understanding of how human-induced pressures and risks impact primate habitat use and activity in anthropogenic landscapes.

The chimpanzee (Pan troglodytes verus) community at Bossou in Guinea, West Africa, is particularly well suited for examining responses to human disturbances and pressures. It has been rated as the most heavily impacted long-term chimpanzee research site (Wilson et al. 2014) and many aspects of chimpanzee ecology and behavior, as well as the practices and cultural beliefs of the local people, are well understood (Matsuzawa et al. 2011). Local people practice slash-and-burn agriculture, which has resulted in a highly heterogeneous anthropogenic landscape (Hockings et al. 2009; Sugiyama and Koman 1992). The density and availability of chimpanzee wild foods vary across forest and anthropogenic habitat types (Bryson-Morrison et al. 2016), and wild fruit availability is highly seasonal (Bryson-Morrison et al. 2016; Hockings et al. 2009; Takemoto 2002; Yamakoshi 1998). The chimpanzees regularly visit cultivated areas to forage on crops and cultivated fruit trees, particularly during seasonal wild fruit scarcity, although they consume some crops regardless of wild fruit availability (Hockings et al. 2009). The chimpanzees crop forage at any time of day, including on occasions when local people are present (Hockings 2007). The chimpanzees at this site are traditionally not hunted or killed because of the totemic beliefs of the local Manon people (Kortlandt 1986; Yamakoshi 2011). However, chimpanzee incursions into cultivated fields are rarely tolerated, and farmers frequently chase them away using noise and/or by throwing stones (Hockings et al. 2009). Two roads dissect the chimpanzees' home range and crossing both these roads is necessary, but risky for them because of the high presence of vehicles and pedestrians (Hockings 2011). In response to these human-induced risks, Bossou chimpanzees display adaptive behaviors and increased frequencies of external signs of anxiety, i.e., rough-self scratching, when foraging in cultivated fields and crossing roads (Hockings 2011; Hockings et al. 2006, 2012).

We aimed to 1) determine Bossou chimpanzees' overall and seasonal patterns of habitat use within their core area with respect to foraging, traveling, resting, and socializing and 2) examine the influences of risky areas, i.e., cultivated fields and human-made roads and paths, on foraging in noncultivated habitat. Given the highly seasonal availability of wild fruits coupled with the chimpanzees' reliance on terrestrial herbaceous vegetation (THV) and cultivars, we predicted that chimpanzee use of forest and highly disturbed 
habitat types for foraging would reflect the spatial and temporal availability of food resources (Bryson-Morrison et al. 2016; Hockings et al. 2009; Takemoto 2002; Yamakoshi 1998). However, owing to the potential risks associated with encountering local people (Hockings 2011; Hockings et al. 2006, 2012), we also predicted that the chimpanzees would prefer habitat types with fewer human-induced pressures and, when foraging in noncultivated habitats, would avoid foraging close to cultivated fields and roads and paths (Cibot et al. 2015; Hockings 2011; Hockings et al. 2006, 2012).

\section{Methods}

\section{Study Site and Population}

We conducted our study in the anthropogenic landscape that surrounds the village of Bossou in the southeastern forest region of the Republic of Guinea, West Africa (latitude $7^{\circ} 38^{\prime} 71.7^{\prime} \mathrm{N}$ and longitude $8^{\circ} 29^{\prime} 38.9^{\prime} \mathrm{W}$ ). Bossou is isolated from the nearest stretch of continuous mature forest in the Nimba Mountain range by $c a .6 \mathrm{~km}$ of savannah. The climate in this region is classified as tropical wet seasonal (Richards 1996), with a short dry season from November to February, when wild fruit availability is highest, and a distinct rainy season from March to October, when wild fruit availability is lower (Bryson-Morrison et al. 2016; Hockings et al. 2009; Humle 2011; Takemoto 2002; Yamakoshi 1998). Four small hills (70-150 m high) surround the village of Bossou and form the core area $\left(c a .6 \mathrm{~km}^{2}\right)$ of the resident chimpanzee community that ranges in this landscape (15 $\mathrm{km}^{2}$ home range) (Humle 2011). During our study (April 2012-March 2013), the chimpanzee community size ranged between 12 and 13 individuals, with 4 adult males and 6 adult females. The Bossou chimpanzees exhibit less fission-fusion than other known communities (Hockings et al. 2012), often traveling and foraging in larger parties than expected relative to community size (Matsuzawa et al. 2011).

\section{Habitat Composition and Food Availability}

We determined habitat composition using quadrat sampling that covered $>70 \%$ $\left(4.3 \mathrm{~km}^{2}\right)$ of the chimpanzees' core area, excluding village areas, roads and paths, and rivers (Bryson-Morrison et al. 2016). Regenerating forest, i.e., young and older growth secondary forest, dominates the landscape, although areas of riverine forest and one small patch of mature forest remain (Bryson-Morrison et al. 2016; Humle 2011). Cultivated fields, coffee plantations, and fallow areas, of various successional stages, occur throughout (Bryson-Morrison et al. 2016; Humle 2011). We included all forest, i.e., mature, riverine, secondary, and young secondary forest, and highly disturbed, i.e., fallow stage 1, 2, and 3; coffee plantations; and cultivated fields, habitat types in our study (Table I) (Bryson-Morrison et al. 2016).

Regenerating and mature forest contain the highest densities of chimpanzee food tree species, while highly disturbed habitat types show relatively low 


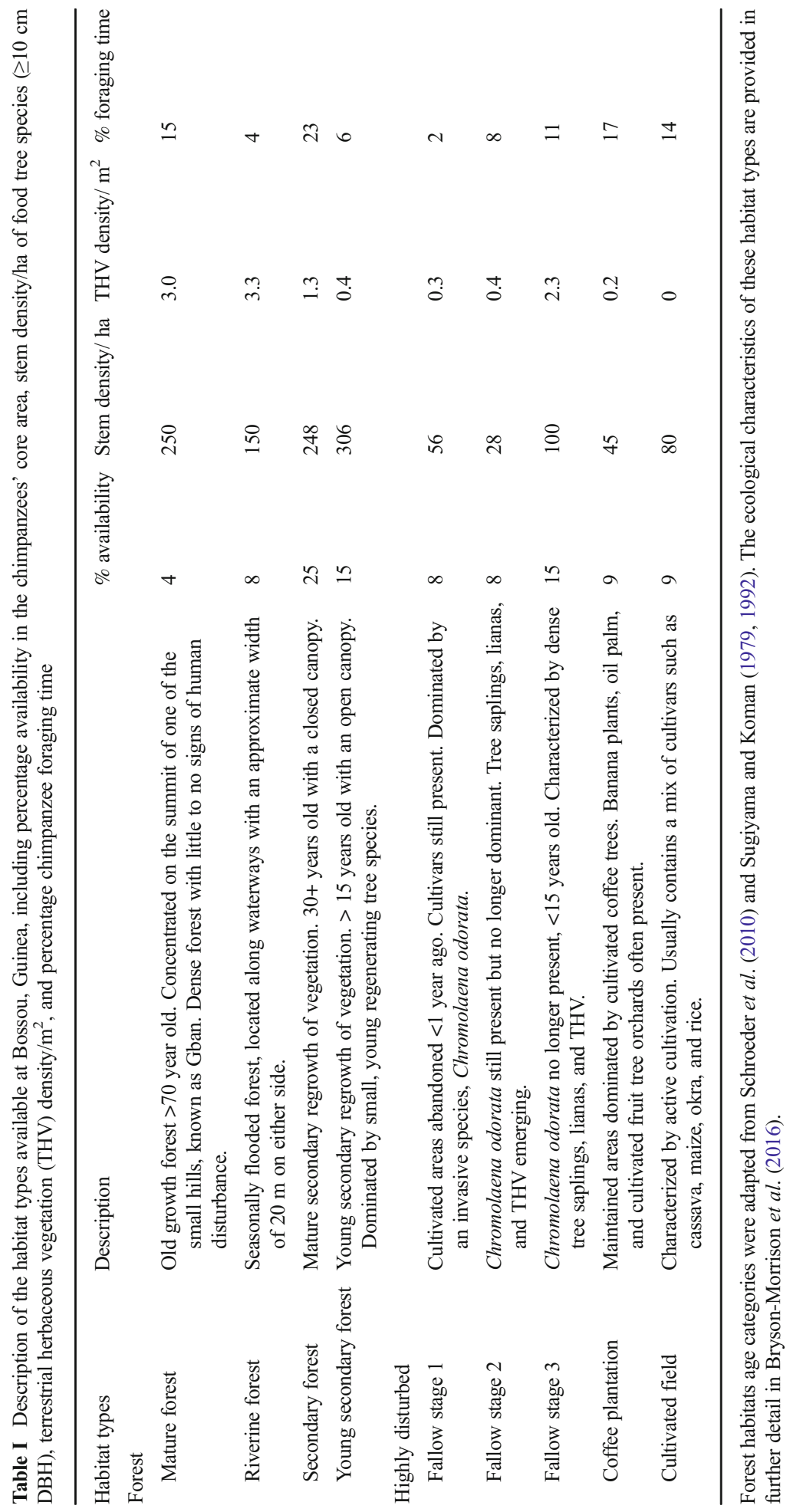


densities (Table I) (Bryson-Morrison et al. 2016). THV occurs in high densities in most forest habitat types, and in fallow stage 3 areas (Table I) (BrysonMorrison et al. 2016; Humle 2011) and is found at relatively low densities in all other highly disturbed habitat types (Table I) (Bryson-Morrison et al. 2016). The majority of cultivated fields in Bossou contain a mix of crops including maize (Zea mays), cassava (Manihot esculenta), okra (Hibiscus esculentus), rice (Oryza sp.), banana (Musa sinensis), and pineapple (Ananasa comosus), all of which provide food parts that are consumed by the chimpanzees (Hockings et al. 2009). In addition to coffee trees (Coffea sp.), most coffee plantations in Bossou contain cultivated fruit tree orchards that provide fruits consumed by the chimpanzees such as orange (Citrus sinensis), mandarin (Citrus reticulata), mango (Mangifera indica), and cacao (Theobroma cacao), as well as banana plants. Unlike cultivated fields, coffee plantations are seldom guarded and the chimpanzees are rarely chased away even when local people are present (Bryson-Morrison pers. obs.). Human-made roads and paths (routes) are found throughout the chimpanzees' home range (Fig. 1). The larger of the two dirt roads ( $c a .12 \mathrm{~m}$ wide) serves as a main thoroughfare from Liberia to the forest region of Guinea and is frequently used by vehicles and pedestrians (Hockings 2011). The smaller road ( $c a .3 \mathrm{~m}$ wide) runs to nearby villages and is used by pedestrians and motorcycles (Hockings 2011). Small paths dissect all four hills and are used by local people for access to forest and agricultural areas.

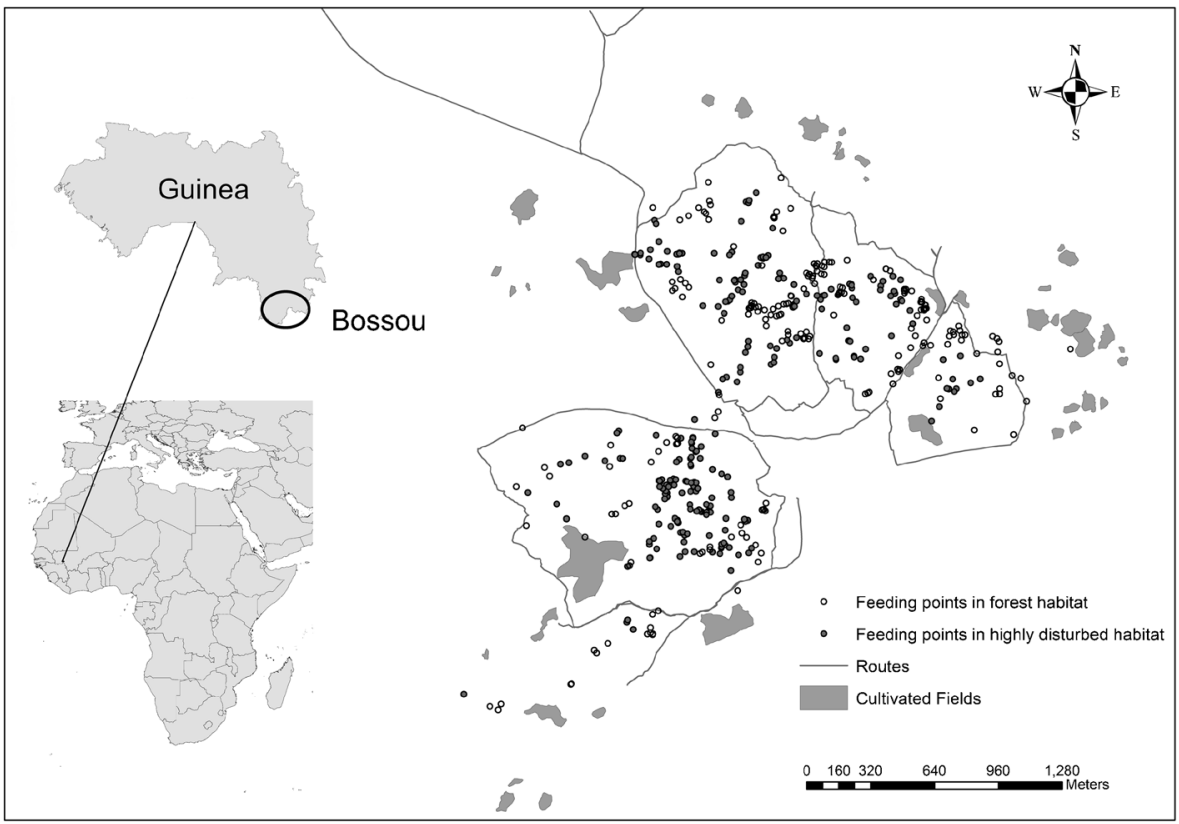

Fig. 1 Map showing the location of all chimpanzee feeding event points $(N=474)$ in forest habitat (mature, riverine, secondary, and young secondary forest) (open circles) and highly disturbed habitat (fallow stage 1, 2, and 3 and coffee plantations) (closed circles) in relation to cultivated fields and routes (all human-made roads and paths) across the chimpanzee core area in Bossou, Guinea, West Africa. We collected feeding event points from April 2012 to March 2013. 


\section{Mapping of Anthropogenic Features}

We mapped routes ( 2 roads, 7 paths) and cultivated fields (43 fields) in the Bossou chimpanzees' core area using a handheld Garmin 62S GPS set to record a point every $10 \mathrm{~m}$ (open canopy accuracy of $\pm 3 \mathrm{~m}$ for GPS points) (Fig. 1).

\section{Behavioral Observations and Feeding Event Locations}

We collected data over a 12-months period from April 2012 to March 2013. We conducted behavioral follows for a maximum of $6 \mathrm{~h} /$ day to comply with site regulations aimed at limiting the time spent observing the chimpanzees. We conducted behavioral follows in the morning between $06: 30$ and 12:30 $\mathrm{h}(N=331 \mathrm{~h})$ or afternoon between 12:30 and 18:30 $\mathrm{h}$ $(N=237 \mathrm{~h}$ ) [total observations: $568 \mathrm{~h}$; wet season (March-October): $440 \mathrm{~h}$; dry season (November-February): $128 \mathrm{~h}$ ]. We began daily follows when we first encountered the chimpanzees. Before each daily follow, we randomly selected an adult focal individual from a predetermined list to record all feeding events using a handheld Garmin 62S GPS. We sampled all adult individuals $(N=10)$ at least once per month. We defined a feeding event as foraging on a single food type and plant part from the same individual tree or food patch. We also recorded habitat type for all feeding events (Table I). Feeding events excluded foraging on crops in cultivated fields, as we avoided following the chimpanzees into these areas during cultivar foraging during our study to minimize the risk that our presence would be viewed negatively by farmers. We observed the chimpanzees from a distance whenever possible to determine their activities within fields; however, this means that we may have underestimated chimpanzee use of cultivated fields. We used focal feeding event points (forest habitat: $N=269$; highly disturbed habitat: $N=205$ ) in spatial analyses to examine the distance from feeding events in noncultivated habitat to cultivated fields and routes. We also conducted 15-min instantaneous scan sampling (Altmann 1974) to record habitat type and activity, i.e., traveling, resting, socializing, and foraging (including actively searching, consuming, and handling food items), for all individuals present in the focal individual's party (mean party size: $6.8 \pm 0.6$ ) (Lehmann et al. 2007). We performed all analyses at the community level because of the small size of the Bossou chimpanzee community at the time of this study.

\section{Data Analyses}

Habitat Use and Preferences To examine chimpanzee habitat selection, we summed the number of 15-min scans in forest habitat, i.e., mature, riverine, secondary, and young secondary forest combined, and highly disturbed habitat, i.e., fallow stage 1, 2, and 3; coffee plantations; and cultivated fields combined, for the entire research period (12 months) and for the wet and dry seasons. We also quantified habitat selection for each of the four mutually exclusive activities (foraging, traveling, resting, and socializing). We then examined habitat selection for each individual habitat type for all activities. Following Manly et al. (2002), we used a Pearson chi-square test to examine the null hypothesis that chimpanzee habitat selection was proportional to habitat availability. Similarly, we used a chi-square test to examine the null hypothesis that chimpanzee activities in each habitat type were proportional to the total number of observations. The results of both the chi-square tests allowed us to examine whether the 
chimpanzees were selectively using or avoiding a particular habitat type by calculating selection ratios using the following equation:

$$
W i=\frac{O i}{\pi i}
$$

where $O i$ is the proportion of observations in habitat type $i$ to the total number of recorded observations and $\pi i$ is the proportion of area comprising habitat type $i$ to the entire area available (Manly et al. 2002). Wi values $>1$ indicate a positive selection for habitat type $i$, values $<1$ indicate a negative selection for habitat type $i$, and values
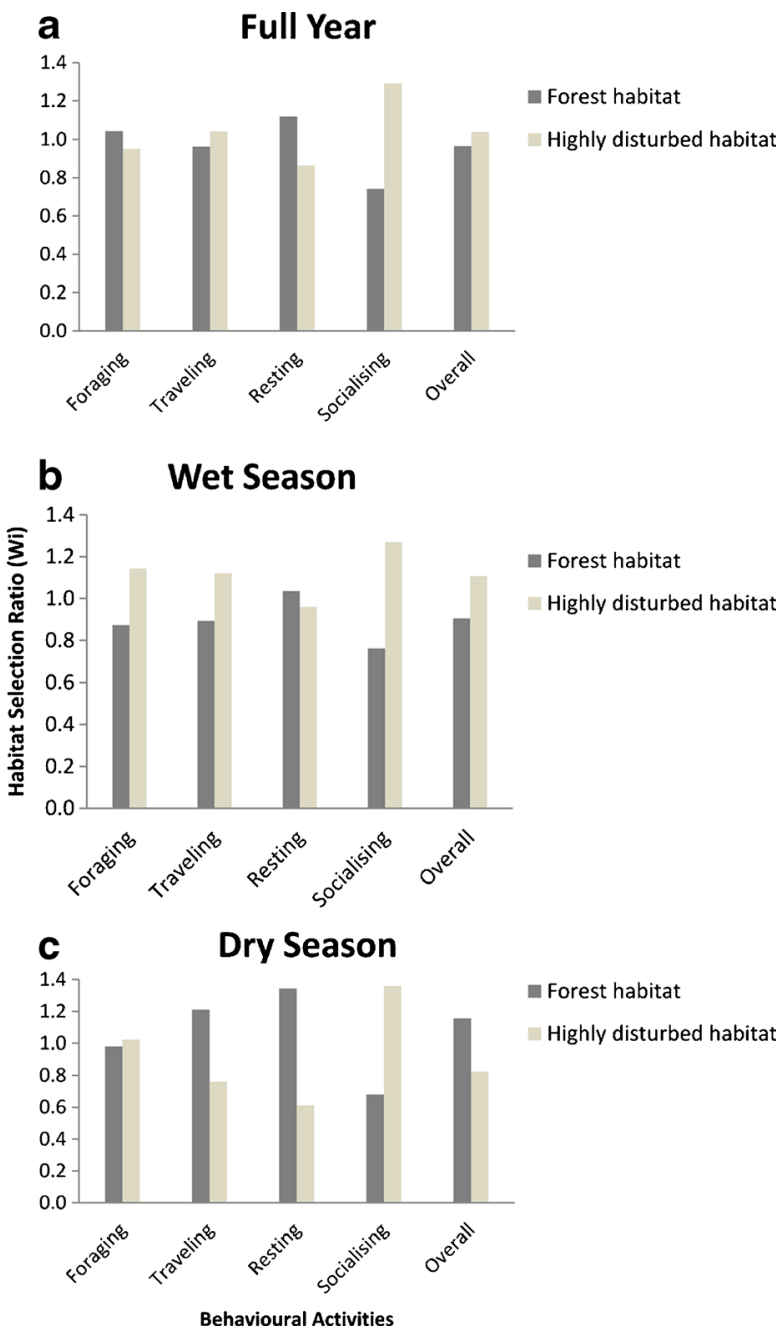

Fig. 2 Habitat selection ratios (Wi) (Manly et al. 2002) for four activities and overall (aggregate of 15-min scans for each habitat type) for the chimpanzee community at Bossou, Guinea, West Africa. a Full year (April 2012-March 2013). b Wet season (March-October). c Dry season (November-February). Forest habitat (mature, riverine, secondary, and young secondary forest) and highly disturbed habitat (fallow stage 1, 2, and 3; coffee plantations; and cultivated fields). 
around 1 indicate that habitat type $i$ was used proportionally to its availability. We standardized selection ratios to allow comparisons between studies using Manly's standardized selection ratio (Manly et al. 2002):

$$
B i=\frac{W i}{\sum_{j=1} W j}
$$

Manly's standardized selection ratio ranges from 0 (no observations in a habitat) to 1 (all observations in a habitat) and provides a measure of the estimated probability that habitat type $i$ would be the next one selected if all habitat types were equally available (Manly et al. 2002). We considered habitat types with the highest selectivity index (Bi) for each activity as preferred habitat for the chimpanzees. We then examined if habitat selection ratios were statistically significant using the following equation:

$$
X^{2}=\left\{\frac{W i-1}{\operatorname{SE}(W i)}\right\}^{2}
$$

where $\mathrm{SE}(W i)$ is the standard error of the selection ratio for habitat type $i$ (Manly et al. 2002). We further compared if selection ratios for each habitat type were significantly different from each other using the following equation:

$$
X^{2}=\frac{(W i-W j)^{2}}{\operatorname{var}(W i-W j)}
$$

where $\operatorname{var}(W i-W j)$ is the variance of the difference between the selection ratios for habitat type $i$ and $j$ (Manly et al. 2002). For all chi-square tests, we applied a $Z$-test with Bonferroni adjusted 95\% confidence intervals of the standardized residuals (Byers et al. 1984; Manly et al. 2002; Neu et al. 1974).

Table II Chimpanzee habitat selection ratios (Wi) (Manly et al. 2002) for each habitat type at Bossou,

\begin{tabular}{|c|c|c|c|c|c|c|c|c|c|c|c|c|c|c|c|}
\hline \multirow[b]{2}{*}{$\begin{array}{l}\text { Habitat } \\
\text { type }\end{array}$} & \multicolumn{3}{|c|}{ Foraging } & \multicolumn{3}{|c|}{ Traveling } & \multicolumn{3}{|c|}{ Resting } & \multicolumn{3}{|c|}{ Socializing } & \multicolumn{3}{|c|}{ Overall } \\
\hline & $\begin{array}{l}\text { Full } \\
\text { year }\end{array}$ & Wet & Dry & $\begin{array}{l}\text { Full } \\
\text { year }\end{array}$ & Wet & Dry & $\begin{array}{l}\text { Full } \\
\text { year }\end{array}$ & Wet & Dry & $\begin{array}{l}\text { Full } \\
\text { year }\end{array}$ & Wet & Dry & $\begin{array}{l}\text { Full } \\
\text { year }\end{array}$ & Wet & Dry \\
\hline MF & 3.68 & 2.62 & 6.75 & 2.86 & 2.29 & 4.36 & 2.75 & 2.01 & 5.42 & 2.31 & 1.63 & 4.41 & 2.86 & 2.11 & 5.27 \\
\hline RVF & 0.41 & 0.37 & 0.51 & 0.55 & 0.55 & 0.54 & 0.47 & 0.34 & 0.93 & 0.61 & 0.61 & 0.61 & 0.49 & 0.41 & 0.74 \\
\hline SF & 0.94 & 1.03 & 0.68 & 1.34 & 1.17 & 1.79 & 1.20 & 1.20 & 1.20 & 0.82 & 0.95 & 0.41 & 1.16 & 1.15 & 1.18 \\
\hline YSF & 0.39 & 0.45 & 0.22 & 0.63 & 0.77 & 0.28 & 0.38 & 0.41 & 0.28 & 0.27 & 0.30 & 0.18 & 0.43 & 0.48 & 0.26 \\
\hline F3 & 0.74 & 0.83 & 0.48 & 0.96 & 0.98 & 0.89 & 1.36 & 1.42 & 1.15 & 1.34 & 1.47 & 0.97 & 1.19 & 1.26 & 0.9 \\
\hline F2 & 1.06 & 1.12 & 0.87 & 1.34 & 1.67 & 0.48 & 1.47 & 1.64 & 0.83 & 1.74 & 2.01 & 0.88 & 1.4 & 1.61 & 0.76 \\
\hline F1 & 0.20 & 0.2 & $0.19 *$ & 0.18 & 0.25 & $0^{*}$ & 0.43 & 0.53 & $0.06^{*}$ & 0.65 & 0.30 & 1.76 & 0.37 & 0.41 & 0.23 \\
\hline $\begin{array}{l}\text { CAF } \\
\text { E }\end{array}$ & 2.17 & 2.55 & 1.06 & 1.04 & 1.14 & 0.77 & 1.03 & 1.05 & 0.95 & 1.58 & 1.37 & 2.25 & 1.24 & 1.30 & 1.05 \\
\hline $\mathrm{CF}$ & 1.7 & 1.28 & 2.99 & 0.72 & 0.75 & 0.67 & 0.65 & 0.70 & 0.48 & 1.09 & 1.04 & 1.27 & 0.86 & 0.82 & 0.99 \\
\hline
\end{tabular}
Guinea, during the wet season (March-October), dry season (November-February), and full year (April 2012March 2013) for four activities and overall (aggregate of 15-min scans)

* Denotes selection ratios that were not significant. Selection ratios highlighted in dark-gray: $W i \geq 2.00$ : highly preferred; mid-gray: $W i=1.20-1.99$ : preferred; light-gray: $W i=0.90-1.19$ : used proportionally to availability; unshaded: $W i=0-0.89$ : avoided. Forest habitat: MF: mature forest; RVF: riverine forest; SF: secondary forest; YSF: young secondary forest; Highly-disturbed habitat: F3: fallow stage 3; F2: fallow stage 2; F1: fallow stage 1; CAFE: coffee plantation; $\mathrm{CF}$ : cultivated field 
Distance of Feeding Events Relative to Cultivated Fields and Routes We used QGis 2.14.0-Essen to calculate the nearest distance $(\mathrm{m})$ of each chimpanzee feeding event point $(N=474)$ to cultivated fields (range: 5.1-681.5 m; mean distance $=352.87 \pm 8.29 \mathrm{~m}$ ) and routes (range: $1.0-593.8 \mathrm{~m}$; mean distance $=$ $170.01 \pm 5.24 \mathrm{~m}$ ) for the full year and for the wet and dry seasons (Fig. 1). We grouped the distance from feeding event points to cultivated fields and routes into 0-100 m, 101-200 m, >200 m categories to facilitate analyses (sensu Lehman et al. 2006). We used a Pearson chi-square test to examine the null hypothesis that the frequency of chimpanzee feeding events was the same for all distance categories to cultivated fields and routes. We then examined the influence of habitat type and season on feeding event distance to cultivated fields and routes using a two-way ANOVA. To meet the assumptions for Levene's test for equality of variance and normality distribution of the data, we removed three outliers and square root transformed the feeding event point distances to routes, and cube transformed the feeding event point distances to cultivated fields. We carried out all statistical analyses using SPSS v. 22 and set the significance level at $P \leq 0.05$.

\section{Ethical Note}

Our study adhered to all research requirements of Guinea, the ethical protocols for research set out by the University of Kent, UK and the Kyoto University Primate Research Institute, Japan, the institution that manages the Bossou fieldsite. The authors have no conflict of interest or competing financial interests to declare.

\section{Results}

\section{Habitat Use and Preferences}

Patterns of Overall Habitat Use Habitat selection ratio (Wi) values for the full year for all chimpanzee activities were similar for forest habitat (mature, riverine, secondary, and young secondary forest combined) $(W i=0.74-1.04)$ and highly disturbed habitat (cultivated fields; coffee plantations; and fallow stages 1,2 , and 3 combined) (Wi=0.86-1.29) (Fig. 2a). Selection ratio values for the wet season suggested that the chimpanzees used highly disturbed habitat marginally more than forest habitat for all activities other than resting (forest habitat range $W i=0.76-0.91$; highly disturbed $W i=0.96-1.27$ ) (Fig. 2b). However, during the dry season, the chimpanzees used forest habitat more for resting and traveling and overall (all activities combined) and used highly disturbed habitat more for socializing (Fig. 2c).

When we examined the Bonferroni adjusted standardized residuals ( $\chi^{2}$ tests) for individual habitat types, selection ratios were significantly different between all habitat types, except between young secondary forest and fallow stage 1, and between fallow 
stage 3 and coffee plantations. Furthermore, selection ratios were significantly different for each of the four activities and overall for all habitat types and all time periods, with the exception of foraging, resting, and traveling in fallow stage 1 during the dry season (Table II and Electronic Supplementary Material Table SI). Overall, mature forest emerged as the most preferred habitat for the chimpanzees with the highest standardized selection ratios $(B i)$ during all time periods (overall: wet season: $B i=0.22$; dry season: $B i=0.46$; full year: $B i=0.29)$. Generally, fallow stage 1 was the least preferred habitat type for the chimpanzees for all activities and time periods (overall: wet season: $B i=0.04$; dry season: $B i=0.02$; full year: $B i=0.04$ ), followed closely by young secondary forest (overall: wet season: $B i=0.04$; dry season: $B i=0.02$; full year: $B i=$ 0.04) (Table SI).

Habitat Preference for Foraging For the forest habitat types and given relative habitat availability, selection ratios revealed that the chimpanzees highly preferred mature forest for foraging during all time periods. Generally, chimpanzees used secondary forest relative to its availability for foraging and avoided riverine and young secondary forest during all time periods. Of the highly disturbed habitat types, chimpanzees preferred coffee plantations and cultivated fields for foraging across the full year, with coffee plantations being highly preferred during the wet season and cultivated fields highly preferred during the dry season. Chimpanzees avoided all stages, i.e., 1, 2, and 3, of fallow habitat for foraging (Tables II and SI).

Habitat Preference for Other Activities. Traveling Chimpanzees highly preferred mature forest for traveling, used secondary forest relative to availability, and avoided riverine and young secondary forest for traveling regardless of season. Generally, they used fallow stage 2 and 3 and coffee plantations relative to availability, except during the dry season, when they avoided these areas. Chimpanzees avoided fallow stage 1 and cultivated fields across all time periods (Tables II and SI).

Resting The chimpanzees highly preferred mature forest for resting during all time periods. They used secondary forest relative to availability across all time periods, and used riverine forest relative to availability during the dry season but avoided it during the wet season and full year. They avoided young secondary forest across all time periods. Generally, the chimpanzees used coffee plantations and fallow stages 3 and stage 2 relative to availability for resting. They avoided fallow stage 1 and cultivated fields for resting during all time periods (Tables II and SI).

Socializing Of the forest habitats, chimpanzees preferred only mature forest for socializing. They used secondary forest relative to availability during the wet season. Of the highly disturbed habitats, the chimpanzees generally preferred socializing in fallow stages 3 and stage 2 and coffee plantations. Generally, chimpanzees used cultivated fields relative to availability and preferred fallow stage 1 for socializing during the dry season but avoided it during the wet season and full year (Tables II and SI). 


\section{Distance of Feeding Events in Noncultivated Habitat Relative to Cultivated Fields and Routes}

There was a significant difference in feeding event distance categories to cultivated fields for the full year and both the wet and dry seasons (full year: $\chi^{2}=433.841, \mathrm{df}=2$, $P<0.0001$; wet season: $\chi^{2}=280.760, \mathrm{df}=2, P<0.0001$; dry season: $\chi^{2}=158.423$, $\mathrm{df}=2, P<0.0001)$. Inspection of the standardized residuals revealed that the chimpanzees fed less than expected by chance at $0-100 \mathrm{~m}$ and $101-200 \mathrm{~m}$ and more than expected by chance $>200 \mathrm{~m}$ away from cultivated fields during the wet and dry seasons and full year. We also found no effect of habitat type or season on feeding event distance to cultivated fields (two-way ANOVA, $F(1,467)=0.430, P=0.512$ ).

There was no significant difference between the observed and expected values for chimpanzee feeding event distance to routes for the wet and dry seasons and full year (full year: $\chi^{2}=1.466, \mathrm{df}=2, P=0.480$; wet season: $\chi^{2}=1.031$, $\mathrm{df}=2, P=0.597$; dry season: $\left.\chi^{2}=0.437, \mathrm{df}=2, P=0.804\right)$. However, the two-way ANOVA revealed a statistically significant interaction between habitat type and season on the distance of feeding events to routes $(F(1,467)=5.227, P=0.023)$. Specifically, the distance of feeding events to routes was greater during the wet season than the dry season in highly degraded habitat. However, there was no effect of season on feeding event distance to routes for forest habitat.

\section{Discussion}

Our study revealed that the chimpanzee community inhabiting the highly heterogeneous anthropogenic landscape of Bossou used different habitat types with varying frequency depending on season and behavioral activity.

\section{Habitat Preference for Foraging}

Our results support the prediction that chimpanzee patterns of habitat use for foraging reflect spatial and temporal food resource availability. Mature forest harbors high densities of chimpanzee food tree species and THV, and the chimpanzees preferentially used this habitat type for foraging throughout the year and especially during the dry season, when wild fruit availability was high (Bryson-Morrison et al. 2016). The chimpanzees also preferentially used cultivated fields for foraging during the dry season, which coincides with the availability of many crops (Hockings et al. 2009). Coffee plantations had the same selection ratio as mature forest during the wet season when wild fruit abundance was lower (Bryson-Morrison et al. 2016). Coffee plantations provide the chimpanzees with easily attainable spatially clumped fruit trees, many of which produce ripe fruit during the wet season, or year round (Bryson-Morrison et al. 2016; Hockings et al. 2009). Furthermore, the chimpanzees generally avoided fallow habitats, which have relatively low food availabilities (Table I) (Bryson-Morrison et al. 2016). Similarly to other chimpanzee communities, Bossou chimpanzees consume a diverse range of foods but maintain a high annual proportion of fruit in their 
diets (Hockings et al. 2009; Takemoto 2002; Yamakoshi 1998), which significantly influenced their habitat use and foraging strategies. These patterns are similar to those reported for other chimpanzee communities, e.g., Caiquene-Cadique, Cantanhez National Park, Guinea-Bissau (Bessa et al. 2015); Bafing Biosphere Reserve, Mali (Duvall 2008); Budongo, Uganda (Tweheyo et al. 2004); and Kahuzi, Democratic Republic of Congo (Basabose 2005). Our study reveals that Bossou chimpanzees specifically prefer mature forest year round for foraging, although they also rely heavily on agricultural habitat to supplement their diets with cultivars. As we did not record all incursions into cultivated fields, we may have underestimated the importance of this habitat type relative to other habitat types.

\section{Habitat Preference for Other Activities}

Our results indicated that Bossou chimpanzees preferred to travel, rest, and socialize in habitat types with less human-induced pressure. Older growth forest (mature and secondary forest) offers greater tree cover (Bryson-Morrison et al. 2016) and little to no human presence, while cultivated fields are relatively open areas (Bryson-Morrison et al. 2016) with high human presence and a high likelihood of antagonistic interactions with humans (Hockings et al. 2007, 2009). Preferential use of mature forest in the dry season, when daily temperatures are high and precipitation low (Humle 2011), for all activities may also reflect an increased requirement for shade. The chimpanzees are known to display thermoregulatory behavior during the dry season by increasing terrestriality to take advantage of cooler temperatures on the ground compared to higher positions in the trees (Takemoto 2004). The high densities of the invasive shrub, Chromolaena odorata, which form dense thickets that are difficult to navigate through, may explain chimpanzees' avoidance of stage 1 fallow (Bryson-Morrison pers. obs.). Nevertheless, our results show that the chimpanzees did not actively avoid all highly disturbed habitat types and used some preferentially, depending on activity and season. Although not examined in the context of specific nonforaging activity patterns, other ecologically flexible primates, such as macaques (Riley 2008) and baboons (Hoffman and O'Riain 2011), often preferentially use human-modified habitats. The high occurrence of social activity in coffee plantations and cultivated fields reflects increased group cohesiveness and social behavior previously reported for Bossou chimpanzees foraging on cultivars (Hockings et al. 2012). Consumption of nutritious energy-rich crops in cultivated areas may allow them more time to engage in other activities, such as socializing, as in populations of baboons, vervets, and macaques consuming human food sources (Altmann and Muruthi 1988; Brennan et al. 1985; Schlotterhausen 2000).

Bossou chimpanzees generally avoided riverine forest habitat. This pattern contrasts with findings from Bulindi, Uganda, where chimpanzees heavily use riverine forest fragments that contain a higher density of feeding trees than the Budongo Forest Reserve, the nearest main forest block (McLennan and Plumptre 2012). Several factors may explain this difference. The density of chimpanzee food tree species in riverine 
forest at Bossou is low compared to that in other forest types (Table I) (BrysonMorrison et al. 2016). Second, riverine forest patches in Bossou are relatively small and often abut cultivated fields, and there is a higher human presence in these areas than within other noncultivated habitat types. This suggests that the availability of a particular habitat type is not necessarily a good indicator of use by chimpanzees, as habitat quality and perceived risks likely vary across sites.

Chimpanzee avoidance of young secondary forest is more difficult to interpret, particularly as this forest type harbors a high density of chimpanzee food species (Bryson-Morrison et al. 2016). The chimpanzees may be selecting older growth forests for feeding on wild fruits as larger trees are known to produce greater fruit yields (Chapman et al. 1992). More detailed phenological surveys of fruiting patterns between habitat types are needed to test this.

\section{Distance of Feeding Events to Cultivated Fields and Routes}

Our results indicated that the chimpanzees significantly preferred foraging on foods in noncultivated habitat at $>200 \mathrm{~m}$ compared to $0-100 \mathrm{~m}$ and $101-200 \mathrm{~m}$ from cultivated fields during all time periods, with no effect of habitat type or season. Wild fruit scarcity during the wet season and ease of access to cultivars did not appear to influence distance of feeding events to cultivated fields, contrasting with findings for the chimpanzee community at Sebitoli, Kibale National Park, Uganda (Bortolamiol et al. 2016). Instead our results suggest that the chimpanzees' preference for foraging on foods in noncultivated habitat at a greater distance to cultivated fields was more likely driven by perceived risks associated with these areas (Hockings 2007, 2011). The nutritional benefits gained from acquiring wild foods close to cultivated fields may not be enough to offset any risks associated with potential human presence, as has been proposed for cultivar foraging (Hockings et al. 2009; McLennan and Hockings 2014; NaughtonTreves et al. 1998). The chimpanzees may therefore be using their environment strategically to balance food acquisition and risk avoidance (Hill 2016). Future studies should aim to collect more detailed phenological data on the availability of food resources at varying distances to cultivated fields, along with behavioral and/or cortisol measures of stress, to investigate fully the effects of risky areas on chimpanzee foraging behavior.

We found no significant difference in chimpanzee feeding event distance to routes (human-made roads and paths). However, the chimpanzees foraged in highly degraded habitat at a greater distance from routes during the wet season than the dry season with no such seasonal effect found for forest habitat. This suggests that the Bossou chimpanzees did not actively avoid foraging close to routes; instead, feeding event distance from routes was likely driven by food availability. Pioneer tree species that produce fruits consumed by the chimpanzees, including Musanga cecropioides, semidomesticated and wild oil palm (Elaeis guineensis), and coffee plantations containing fruit orchards and banana plants, are found at the sides of roads and paths (Bryson-Morrison pers. obs.). Road crossing is risky for wildlife, including primates (Cibot et al. 2015; Gunson et al. 2011; Jaegger et al. 2005; McLennan and Asiimwe 2016); however, roadsides can also represent areas of high vegetation species richness, attracting wildlife (Forman and Alexander 1998). Indeed, findings from Sebitoli, 
Kibale National Park, Uganda indicated that proximity to a tarmac road, where roadside management strategies favor the growth of THV, was one of the main predictors of chimpanzee distribution (Bortolamiol et al. 2016).

\section{Implications for Chimpanzee Conservation in Anthropogenic Landscapes}

Overall, our study clearly indicated that chimpanzees at Bossou show a high preference for mature forest. Local people rarely gather nontimber forest products from, or enter, this single small patch of mature forest as they regard it as sacred (Kortlandt 1986; Yamakoshi 2005). We also found chimpanzees rarely use riverine forest at Bossou, probably because this combines relatively low food availability with high human presence. Our results suggest that chimpanzees in human-dominated environments prefer habitat types where a plentiful supply of wild foods is coupled with low human presence for most activities. The availability of such "refuges" may be critical to the long-term persistence of chimpanzee populations within anthropogenic landscapes.

Alongside older-growth forest (mature and secondary forest), the chimpanzees at Bossou preferentially used cultivated habitat for foraging throughout the year. Chimpanzee reliance on crops to supplement wild foods in forest-agricultural mosaics complicates humanchimpanzee coexistence and requires careful management (Hill and Wallace 2012). Restoration or recovery of abandoned agricultural areas to forest may reduce reliance on cultivated food, but this will likely depend on how important crops are in the diet of a given population, as well as the degree of perceived risk associated with cultivar foraging in agricultural habitats (Hockings and McLennan 2012; McLennan and Hockings 2014). Moreover, reforestation of abandoned agricultural areas can take many years (Aide et al. 2000; Chapman and Chapman 1999) and young successional habitat types may be the only available habitats for resident chimpanzees in the interim. Our study showed that chimpanzees generally avoided using young regenerating habitat types (fallow and young secondary forest), suggesting that widespread agricultural conversion and subsequent expansion of new fallow areas could prove detrimental for the long-term survival of chimpanzees, as for other primate populations (Ancrenaz et al. 2015; Palm et al. 2013; Wich et al. 2014).

In conclusion, our study reveals that the risks associated with some anthropogenic features may influence important behavioral activities, such as foraging. These findings contribute to our understanding of chimpanzee behavioral responses to human encounters and pressures in their environment. Our study further demonstrates the value of determining which habitat types are avoided or preferred, and potentially necessary, for chimpanzees in anthropogenic landscapes. We suggest that it is crucial to determine relative reliance on available habitat types, as well as agricultural areas, when devising conservation strategies for chimpanzee and other primate populations residing in anthropogenic landscapes.

Acknowledgements We thank the Institut de Recherche Environmentale de Bossou and the Direction Nationale de la Recherche Scientifique et Technologique for permission to conduct this study. Funding was provided in part by a MEXT 24000001 grant to T. Matsuzawa and a grant in aid of research from Sigma-Xi the Scientific Research Society. We thank all the field guides at Bossou who assisted with data collection. We are grateful to N. Morimura for kindly providing us with maps of the human-made roads and paths found at Bossou. We are also grateful to K. J. Hockings and G. Yamakoshi for useful discussion on the ecology of Bossou chimpanzees. We thank the editors and two anonymous reviewers for helpful comments on this manuscript. 
Open Access This article is distributed under the terms of the Creative Commons Attribution 4.0 International License (http://creativecommons.org/licenses/by/4.0/), which permits unrestricted use, distribution, and reproduction in any medium, provided you give appropriate credit to the original author(s) and the source, provide a link to the Creative Commons license, and indicate if changes were made.

\section{References}

Aide, T. M., Zimmerman, J. K., Pascarella, J. B., Rivera, L., \& Marcano-Vega, H. (2000). Forest regeneration in a chronosequence of tropical abandoned pastures: implications for restoration ecology. Restoration Ecology, 8, 328-338.

Altmann, J. (1974). Observational study of behavior: sampling methods. Behaviour, 49, 227-267.

Altmann, J., \& Muruthi, P. (1988). Differences in daily life between semiprovisioned and wild-feeding baboons. American Journal of Primatology, 15, 213-221.

Ancrenaz, M., Cheyne, S. M., Humle, T., \& Robbins, M. M. (2015). Impacts of industrial agriculture on ape ecology. In A. Foundation (Ed.), State of the apes (Industrial agriculture and ape conservation, Vol. II, pp. 165-192). Cambridge: Cambridge University Press.

Basabose, A. K. (2005). Ranging patterns of chimpanzees in a montane forest of kahuzi, Democratic Republic of Congo. International Journal of Primatology, 26, 33-54.

Bessa, J., Sousa, C., \& Hockings, K. J. (2015). Feeding ecology of chimpanzees (Pan troglodytes verus) inhabiting a forest-mangrove-savanna-agricultural-matrix at Caiquene-Cadique, Cantanhez National Park, Guinea-Bissau. American Journal of Primatology, 77, 651-665.

Blake, S., Strindberg, S., Boudjan, P., Makombo, C., Bila-Isia, I., et al. (2007). Forest elephant crisis in the Congo Basin. PLoS Biology, 5, e111.

Bortolamiol, S., Cohen, M., Jiguet, F., Pennec, F., Seguya, A., \& Krief, S. (2016). Chimpanzee non-avoidance of hyper-proximity to humans. The Journal of Wildlife Management, 80, 924-934.

Brennan, E., Else, J., \& Altmann, J. (1985). Ecology and behaviour of a pest primate: vervet monkeys in a tourist-lodge habitat. African Journal of Ecology, 23, 35-44.

Brncic, T., Amarasekaran, B., \& McKenna, A. (2010). Sierra Leone national chimpanzee census. Freetown: Tacugama Chimpanzee Sanctuary.

Brncic, T., Amarasekaran, B., McKenna, A., Mundry, R., \& Kuhl, H. S. (2015). Large mammal diversity and their conservation in the human-dominated land-use mosaic of Sierra Leone. Biodiversity and Conservation, 24, 2417-1438.

Bryson-Morrison, N., Matsuzawa, T., \& Humle, T. (2016). Chimpanzees in an anthropogenic landscape: examining food resources across habitat types at Bossou, Guinea, West Africa. American Journal of Primatology, 78, 1237-1249.

Byers, C. R., Steinhorst, R. K., \& Krausman, P. R. (1984). Clarification of a technique for analysis of utilization-availability data. Journal of Wildlife Management, 48, 1050-1053.

Campbell-Smith, G., Campbell-Smith, M., Singleton, I., \& Linkie, M. (2011). Raiders of the lost bark: orangutan foraging strategies in a degraded landscape. PLOS ONE, 6, e20962.

Chapman, C. A., \& Chapman, L. J. (1999). Forest restoration in abandoned agricultural land: a case study from East Africa. Conservation Biology, 13, 1301-1311.

Chapman, C. A., Chapman, L. J., Wrangham, R., Hunt, K., Gebo, D., \& Gardner, L. (1992). Estimators of fruit abundance of tropical trees. Biotropica, 24, 527-531.

Chapman, C. A., \& Peres, C. A. (2001). Primate conservation in the new millennium: the role of scientists. Evolutionary Anthropology, 10, 16-33.

Cibot, M., Bortolamiol, S., Seguya, A., \& Krief, S. (2015). Chimpanzees facing a dangerous situation: a hightraffic asphalted road in the sebitoli area of kibale national park, Uganda. American Journal of Primatology, 77, 890-900.

Cowlishaw, G. (1997). Trade-offs between foraging and predation risk determine habitat use in a desert baboon population. Animal Behaviour, 53, 667-686.

Cyr, N., \& Romero, L. (2008). Fecal glucocorticoid metabolites of experimentally stressed captive and freeliving starlings: implications for conservation research. General Comparative Endocrinology, 158, 20-28.

Duvall, C. S. (2008). Human settlement ecology and chimpanzee habitat selection in Mali. Landscape Ecology, 23, 699-716.

Estrada, A. (2013). Socioeconomic contexts of primate conservation: population, poverty, global economic demands, and sustainable land use. American Journal of Primatology, 75, 30-45. 
Forman, R. T., \& Alexander, L. E. (1998). Roads and their major ecological effects. Annual Review of Ecology and Systematics, 29, 207-231.

Fourie, N. H., Turner, T. R., Brown, J. L., Pampush, J. D., Lorenz, J. G., \& Bernstein, R. M. (2015). Variation in vervet (Chlorocebus aethiops) hair cortisol concentrations reflects ecological disturbance by humans. Primates, 56, 365-373.

Gabriel, D. N. (2013). Habitat use and activity patterns as an indication of fragment quality in a strepsirrhine primate. International Journal of Primatology, 34, 388-406.

Gunson, K. E., Mountrakis, G., \& Quackenbush, L. J. (2011). Spatial wildlife-vehicle collision models: a review of current work and its application to transportation mitigation projects. Journal of Environmental Management, 92, 1074-1082.

Guzmán, A., Link, A., Castillo, J. A., \& Botero, J. E. (2016). Agroecosystems and primate conservation: shade coffee as potential habitat for the conservation of Andean night monkeys in the Northern Andes. Agriculture, Ecosystems \& Environment, 215, 57-67.

Heiduck, S. (2002). The use of disturbed and undisturbed forest by masked titi monkeys Callicebus personatus melanochir is proportional to food availability. Oryx, 36, 133-139.

Hickey, J. R., Nackoney, J., Nibbelink, N. P., Blake, S., Bonyenge, A., et al. (2013). Human proximity and habitat fragmentation are key drivers of the rangewide bonobo distribution. Biodiversity and Conservation, 22, 3085-3104.

Hicks, T. C., Roessingh, P., \& Menken, S. B. J. (2012). Reactions of Bili-uele chimpanzees to humans in relation to their distance from roads and villages. American Journal of Primatology, 74, 721-733.

Hill, C. M. (2000). Conflict of interest between people and baboons: crop raiding in Uganda. International Journal of Primatology, 21, 299-315.

Hill, C. M. (2005). People, crops, and primates: A conflict of interests. In J. D. Paterson \& J. Wallis (Eds.), Commensalism and conflict: The primate-human interface. Winnipeg: Higwell Printing.

Hill, C. M., \& Wallace, G. E. (2012). Crop protection and conflict mitigation: reducing the costs of living alongside non-human primates. Biodiversity and Conservation, 21, 2569-2587.

Hill, C. M., \& Webber, A. D. (2010). Perceptions of nonhuman primates in human-wildlife conflict scenarios. American Journal of Primatology, 72, 919-924.

Hill, R. A. (2016). Nonhuman primate approaches to landscapes. In B. David \& J. Thomas (Eds.), Handbook of landscape archaeology (pp. 95-101). New York: Routledge.

Hockings, K.J. (2007). Human-chimpanzee coexistence at Bossou, the Republic of Guinea: A chimpanzee perspective. Ph.D. thesis, University of Stirling.

Hockings, K. J. (2011). Behavioral flexibility and division of roles in chimpanzee road-crossing. In T. Matsuzawa, T. Humle, \& Y. Sugiyama (Eds.), The chimpanzees of Bossou and Nimba (pp. 221-229). London: Springer.

Hockings, K. J., Anderson, J. R., \& Matsuzawa, T. (2006). Road-crossing in chimpanzees: a risky business. Current Biology, 16, 668-670.

Hockings, K. J., Anderson, J. R., \& Matsuzawa, T. (2009). Use of wild and cultivated foods by chimpanzees at Bossou, Republic of Guinea: feeding dynamics in a human-influenced environment. American Journal of Primatology, 71, 636-646.

Hockings, K. J., Anderson, J. R., \& Matsuzawa, T. (2012). Socioecological adaptations by chimpanzees, Pan troglodytes verus, inhabiting an anthropogenically impacted habitat. Animal Behaviour, 83, 801-810.

Hockings, K. J., Humle, T., Anderson, J. R., Biro, D., Sousa, C., Ohashi, G., \& Matsuzawa, T. (2007). Chimpanzees share forbidden fruit. PLoS ONE, 2, e886.

Hockings, K. J., \& McLennan, M. R. (2012). From forest to farm: systematic review of cultivar feeding by chimpanzees - management implications for wildlife in anthropogenic landscapes. PLoS ONE, 7, e33391.

Hockings, K. J., McLennan, M. R., Carvalho, S., Ancrenaz, M., Bobe, R., et al. (2015). Apes in the anthropocene: flexibility and survival. Trends in Ecology \& Evolution, 30, 215-222.

Hockings, K. J., \& Sousa, C. (2013). Human-chimpanzee sympatry and interactions in Cantanhez National Park, Guinea-Bissau: current research and future directions. Primate Conservation, 26, 57-65.

Hoffman, T. S., \& O'Riain, M. J. (2011). The spatial ecology of chacma baboons (Papio ursinus) in a humanmodified environment. International Journal of Primatology, 32, 308-328.

Humle, T. (2011). Location and ecology. In T. Matsuzawa, T. Humle, \& Y. Sugiyama (Eds.), The chimpanzees of Bossou and Nimba (pp. 13-21). London: Springer.

Isabirye-Basuta, G. M., \& Lwanga, J. S. (2008). Primate populations and their interactions with changing habitats. International Journal of Primatology, 29, 35-48. 
Jaegger, J. A. G., Bowman, J., Brennan, J., Fahrig, L., Bert, D., et al. (2005). Predicting when animal populations are at risk from roads: an interactive model of road avoidance behavior. Ecological Modelling, 185, 329-348.

Junker, J., Blake, S., Boesch, C., Campbell, G., Toit, L. D., et al. (2012). Recent decline in suitable environmental conditions for African great apes. Diversity and Distributions, 18, 1077-1091.

Kortlandt, A. (1986). The use of stone tools by wild-living chimpanzees and earliest hominids. Journal of Human Evolution, 15, 77-132.

Krief, S., Cibot, M., Bortolamiol, S., Seguya, A., Krief, J. M., \& Masi, S. (2014). Wild chimpanzees on the edge: nocturnal activities in croplands. PLOS ONE, 9, e109925.

Lambert, J. E., \& Rothman, J. M. (2015). Fallback foods, optimal diets, and nutritional targets: primate responses to varying food availability and quality. Annual Review of Anthropology, 44, 493-512.

Lee, R.J. (1997). The impact of hunting and habitat disturbance on the population dynamics and behavioral ecology of the crested black macaque (Macaca nigra). Ph.D. thesis, University of Oregon, Eugene.

Lehman, S. M., Rajaonson, A., \& Day, S. (2006). Edge effects and their influence on lemur density and distribution in southeast Madagascar. American Journal of Physical Anthropology, 129, 232-241.

Lehmann, J., Korstjens, A. H., \& Dunbar, R. (2007). Fission-fusion social systems as a strategy for coping with ecological constraints: a primate case. Evolutionary Ecology, 21, 613-634.

Leighton, M. (1993). Modeling dietary selectivity by Bornean orangutans: evidence for integration of multiple criteria in fruit selection. International Journal of Primatology, 14, 257-313.

Li, Y. (2004). The effect of forest clear-cutting on habitat use in Sichuan snub-nosed monkey (Rhinopithecus roxellana) in Shennongjia Nature Reserve, China. Primates, 45, 69-72.

Manly, B. F. J., McDonald, L. L., Thomas, D. L., McDonald, T. L., \& Erickson, W. P. (2002). Resource selection by animals: Statistical design and analysis for field studies (2nd ed.). Dordrecht: Kluwer Academic.

Matsuzawa, T., Humle, T., \& Sugiyama, Y. (Eds.). (2011). The chimpanzees of Bossou and Nimba. London: Springer.

McKinney, T. (2011). The effects of provisioning and crop-raiding on the diet and foraging activities of human-commensal white-faced capuchins (Cebus capucinus). American Journal of Primatology, 73, 439-448.

McLennan, M. R. (2013). Diet and feeding ecology of chimpanzees (Pan troglodytes) in Bulindi, Uganda: foraging strategies at the forest-farm interface. International Journal of Primatology, 34, 585-614.

McLennan, M. R., \& Asiimwe, C. (2016). Cars kill chimpanzees: case report of a wild chimpanzee killed on a road at Bulindi, Uganda. Primates, 57, 377-388.

McLennan, M. R., \& Hockings, K. J. (2014). Wild chimpanzees show group differences in selection of agricultural crops. Scientific Reports, 4, 5956.

McLennan, M. R., \& Plumptre, A. J. (2012). Protected apes, unprotected forest: composition, structure and diversity of riverine forest fragments and their conservation value in Uganda. Tropical Conservation Science, 5, 79-103.

Ménard, N., Motsch, P., Delahaye, A., Saintvanne, A., Le Flohic, G., et al. (2014). Effect of habitat quality on diet flexibility in Barbary macaques. American Journal of Primatology, 76, 679-693.

Muyambi, F. (2005). The impact of tourism on the behaviour of mountain gorillas. Gorilla Journal, 30, 14-15.

Naughton-Treves, L., Treves, A., Chapman, C., \& Wrangham, R. (1998). Temporal patterns of crop-raiding by primates: linking food availability in croplands and adjacent forest. Journal of Applied Ecology, 35, 596606.

Neu, C. W., Byers, C. R., \& Peek, J. M. (1974). A technique for analyses of utilization-availability data. Journal of Wildlife Management, 38, 541-545.

O’Brien, T. G., \& Kinnaird, M. F. (1997). Behavior, diet, and movements of the Sulawesi crested black macaque. International Journal of Primatology, 18, 321-351.

Palm, C. A., Vosti, S. A., Sanchez, P. A., \& Ericksen, P. J. (2013). Slash-and-burn agriculture: the search for alternatives. New York: Columbia University Press.

Palminteri, S., \& Peres, C. A. (2012). Habitat selection and use of space by bald-faced sakis (Pithecia irrorata) in Southwestern Amazonia: Lessons from a multiyear, multigroup study. International Journal of Primatology, 33, 401-417.

Plumptre, A., Rose, R., Nangendo, G., Williamson, E. A., Didier, K., et al. (2010). Eastern chimpanzee (Pan troglodytes schweinfurthii): Status survey and conservation action plan 2010-2020. Gland, Switzerland: IUCN.

Porter, L. L., Sterr, S. M., \& Garber, P. A. (2007). Habitat use and ranging behavior of Callimico goeldii. International Journal of Primatology, 28, 1035-1058. 
Poulsen, J., Clark, C., Mavah, G., \& Elkan, P. (2009). Bushmeat supply and consumption in a tropical logging concession in northern Congo. Conservation Biology, 23, 1597-1608.

Pozo-Montuy, G., Serio-Silva, J. C., Chapman, C. A., \& Bonilla-Sánchez, Y. M. (2013). Resource use in a landscape matrix by an arboreal primate: evidence of supplementation in black howlers (Alouatta pigra). International Journal of Primatology, 34, 714-731.

Raboy, B. E., \& Dietz, J. M. (2004). Diet, foraging, and use of space in wild golden-headed lion tamarins. American Journal of Primatology, 63, 1-15.

Rangel-Negrín, A., Alfaro, J., Valdez, R., Romano, M., \& Serio-Silva, J. (2009). Stress in Yucatan spider monkeys: effects of environmental conditions on fecal cortisol levels in wild and captive populations. Animal Conservation, 12, 496-502.

Richards, P. W. (1996). The tropical rainforest (2nd ed.). New York: Cambridge University Press.

Riley, E. P. (2007). The human-macaque interface: conservation implications of current and future overlap and conflict in Lore Lindu National Park, Sulawesi, Indonesia. American Anthropologist, 109, 473-484.

Riley, E. P. (2008). Ranging patterns and habitat use of Sulawesi Tonkean macaques (Macaca tonkeana) in a human-modified habitat. American Journal of Primatology, 70, 670-679.

Robinson, J. G., Redford, K. H., \& Bennett, E. L. (1999). Wildlife harvest in logged tropical forests. Science, 284, 595-596.

Saj, T., Sicotte, P., \& Paterson, J. D. (1999). Influence of human food consumption on the time budget of vervets. International Journal of Primatology, 20, 977-994.

Sakura, O. (1994). Factors affecting party size and composition of chimpanzees (Pan troglodytes verus) Bossou, Guinea. International Journal of Primatology, 15, 167-183.

Sapolsky, R. M., Romero, L. M., \& Munck, A. U. (2000). How do glucocorticoids influence stress responses? Integrating permissive, suppressive, stimulatory, and preparative actions. Endocrine Reviews, 21, 55-89.

Sawyer, S. C., \& Brashares, J. S. (2013). Applying resource selection functions at multiple scales to prioritize habitat use by the endangered cross river gorilla. Diversity and Distributions, 19, 943-954.

Schlotterhausen, L. (2000). Town monkeys, country monkeys: A socioecological comparison of a human commensal and wild group of bonnet macaques (Macaca radiata). Ph.D. thesis, New York University.

Schroeder, J., Oke, D., Onyekwelu, J., \& Yirdaw, E. (2010). Secondary forests in West Africa: A challenge and opportunity for management. In G. Mery, P. Katila, G. Galloway, R. Alfaro, \& M. Kanninen (Eds.), Forests and society-responding to global drivers of change 25 (pp. 335-353). Vienna: IUFRO World Series.

Sha, J. C. M., \& Hanya, G. (2013). Diet, activity, habitat use, and ranging of two neighboring groups of foodenhanced long-tailed macaques (Macaca fascicularis). American Journal of Primatology, 75, 581-592.

Singh, M., Kumara, H., Kumar, M. A., \& Sharma, A. K. (2001). Behavioural responses of lion-tailed macaques (Macaca silenus) to a changing habitat in a tropical rain forest fragment in the Western Ghats, India. Folia Primatologica, 72, 278-291.

Sugiyama, Y., \& Koman, J. (1979). Social structure and dynamics of wild chimpanzees at Bossou, Guinea. Primates, 20, 323-339.

Sugiyama, Y., \& Koman, J. (1992). The flora of Bossou: its utilization by chimpanzees and humans. African Study Monographs, 13, 127-169.

Takemoto, H. (2002). Feeding ecology of chimpanzees in Bossou, Guinea: Coping with the seasonal fluctuation of food supply and micrometeorology in the tropical forest. Ph.D. thesis, Kyoto University.

Takemoto, H. (2004). Seasonal change in terrestriality of chimpanzees in relation to microclimate in the tropical forest. American Journal of Physical Anthropology, 124, 81-92.

Terada, S., Nackoney, J., Sakamaki, T., Mulavwa, M. N., Yumoto, T., \& Furuichi, T. (2015). Habitat use of bonobos (Pan paniscus) at Wamba: selection of vegetation types for ranging, feeding, and night-sleeping. American Journal of Primatology, 77, 701-713.

Tutin, C. E. (1999). Fragmented living: behavioural ecology of primates in a forest fragment in the Lopé reserve, Gabon. Primates, 40, 249-265.

Tweheyo, M., Hill, C. M., \& Obua, J. (2005). Patterns of crop raiding by primates around the Budongo Forest Reserve, Uganda. Wildlife Biology, 11, 237-247.

Tweheyo, M., Lye, K. A., \& Weladji, R. B. (2004). Chimpanzee diet and habitat selection in the Budongo Forest Reserve, Uganda. Forest Ecology and Management, 188, 267-278.

van Gils, H., \& Kayijamahe, E. (2010). Sharing natural resources: mountain gorillas and people in the Parc National des Volcans, Rwanda. African Journal of Ecology, 48, 621-627.

Wich, S., Garcia-Ulloa, J., Kühl, H., Humle, T., Lee, J. H., \& Koh, L. (2014). Will oil palm’s homecoming spell doom for Africa's great apes? Current Biology, 24, 1659-1663. 
Wich, S. A., Gaveau, D., Abram, N., Ancrenaz, M., Baccini, A., et al. (2012). Understanding the impacts of land-use policies on a threatened species: is there a future for the Bornean orangutan? PLoS ONE, 7, e49142.

Wilson, M. L., Boesch, C., Fruth, B., Furuichi, T., Gilby, I. C., et al. (2014). Lethal aggression in Pan is better explained by adaptive strategies than human impacts. Nature, 513, 414-417.

Wilson, M. L., Hauser, M. D., \& Wrangham, R. W. (2007). Chimpanzees (Pan troglodytes) modify grouping and vocal behavior in response to location-specific risk. Behaviour, 144, 1621-1653.

Wingfield, J., \& Romero, L. (2010). Adrenocortical responses to stress and their modulation in free-living vertebrates. Comprehensive Physiology, Supplement 23: Handbook of Physiology, the Endocrine System, Coping with the Environment: Neural and Endocrine Mechanisms, 211-234.

Wong, S. N., Saj, T. L., \& Sicotte, P. (2006). Comparison of habitat quality and diet of Colobus vellerosus in forest fragments in Ghana. Primates, 47, 365-373.

Yamakoshi, G. (1998). Dietary responses to fruit scarcity of wild chimpanzees at Bossou, Guinea: possible implications for ecological importance of tool use. American Journal of Physical Anthropology, 106, 283-295.

Yamakoshi, G. (2005). What is happening on the border between humans and chimpanzees? Wildlife conservation in West African rural landscapes. In K. Hiramatsu (Ed.), Coexistence with nature in a 'glocalizing' world: Field science perspectives. Proceedings of the 7th Kyoto University International Symposium (pp. 91-97). Kyoto: Kyoto University.

Yamakoshi, G. (2011). Looking back on three decades of research on Bossou chimpanzees. In T. Matsuzawa, T. Humle, \& Y. Sugiyama (Eds.), The chimpanzees of Bossou and Nimba (pp. 13-21). London: Springer. 